\title{
Discontinuation of Tnf-Alfa Inhibitors in Rheumatoid Arthritis Remission
}

\author{
Izabela Domyslawska*, Ewa Gindzienska-Sieskiewicz, Tomasz Chrostowski, Piotr A. Klimiuk and Stanisław Sierakowski
}

Department of Rheumatology and Internal Diseases, University Hospital in Bialystok, Poland

\begin{abstract}
Objectives: The process of medication for patients with Rheumatoid arthritis until the moment of remission is well-described. However, there is a lack of detailed recommendations as to how to proceed from that point on.

Methods: Our trial produced data for analysis of durability of remission with discontinued biological drugs. We used data from patients treated in the Department of Rheumatology in Bialystok. Patient's $\geq 18$ years with a diagnosis of severe active RA. Patients received biological treatment according to Polish National Health Service guidelines and were monitored every 3 months.

Results: 141 patients met the sample selection criteria. The median time of first-line therapy in our study was 378.5 days. Secondary failure of initial response to treatment was observed in $5.67 \%$ of the patients. 118 patients $(83.68 \%)$ responded to treatment with first-line biological DMARD, the median time to achieve remission or low disease activity - was 198 days. DAS28 remission was achieved in approximately $54 \%$ of patients, and low disease activity was obtained in $29 \%$ of patients. In this group the median time to discontinuation of treatment was 452.4 day. After discontinuation of therapy relapse occurred in 104 of 139 patients (74.28\%). Disease recurrence within 12 months after the end of treatment was observed in an average 110.4 days. The time to reach the next remission in this group of patients was on average 211 days. A proportion of patients who achieved remission and low disease activity with respect to first-line treatment was significantly lower (33\% compared to $49 \%$ ).
\end{abstract}

Keywords: Rheumatoid arthritis; Autoimmune disorder; Inflammatory; Tumour necrosis factor; Biological drugs; Disease modifying anti-rheumatic drugs

\section{Introduction}

Rheumatoid arthritis (RA) is a systemic, inflammatory, autoimmune disorder. RA has many deleterious consequences, such as persistent pain, functional impairment, fatigue and depression. Disability caused by RA leads to a significant reduction in quality of life and has negative economic impact. Enhanced understanding of the underlying mechanisms has facilitated the development of biological drugs, particularly antibodies against tumour necrosis factor, interleukin- 6 and CD20 protein. Treatment with these drugs proved to be clinically effective and has changed outcomes for patients and society [1-3].

According to the European League Against Rheumatism (EULAR) recommendations for the management of rheumatoid arthritis with synthetic and biological disease-modifying antirheumatic drugs (2013 update), treatment should be aimed at reaching a target of remission or low disease activity in every patient in as short a time as possible [4].

Disease-modifying antirheumatic drugs (DMARDs), among which are synthetic (sDMARDs), targeted synthetic (tsDMARDs) and biological (bDMARDs), are to be introduced as soon as the diagnosis of RA is made. Patients are to be monitored frequently to evaluate efficacy and risks, changing types of drugs if there is no improvement by at most 3 months after treatment start or the target has not been reached by 6 months. Synthetic drugs, prominently Methotrexate (MTX), are the basis and first option of therapy, though many patients require the addition of biological medication (bDMARDs) to achieve a clinical improvement [4]. The process of medication until the moment of remission is well-described, but there is a lack of detailed recommendations as to how to proceed from that point on. No specified conditions or algorithms are presented and there is no minimal or maximal time for conducting (bDMARDs) therapy. Considering the fact that biological drugs bear a risk of serious adverse effects and their high cost is a non-negligible socio-economic burden, a question arises: is discontinuing biological bDMARDs in patients with remission a viable option?

Polish National Health Service guidelines state that bDMARDs shall be stopped in patients with remission if the following criteria are fulfilled: there was a state of low disease activity for over 6 months, what is indicated by Disease Activity Score (DAS28 score) $<3.2$ or DAS score $<2,4$ [5]. In such case bDMARDs treatment is discontinued and sequential therapy includes sDMARDs, preferably MTX. Patients are to be monitored and if the values of DAS2 8 rise by over 1.2 , total value over 3.7 bDMARDs therapy is to be renewed [5].

This trial produced data for analysis of durability of remission with discontinued biological drugs. As cessation of rheumatoid arthritis treatment with bDMARDs may result in significant probability of recurrence, we wanted to study the validity of such policy and assess the risks involved.

\section{Patients and Methods}

This study used data from patients treated in the Department of Rheumatology at the University Hospital in Bialystok, acquired between 2006 and 2014 .

*Corresponding author: Izabela Domyslawska, Department of Rheumatology and Internal Diseases, University Hospital in Bialystok, UI. Marii SkłodowskiejCurie 24A, 15-276, Białystok, Poland, Tel: +48-85-7468482, +48-603-99-55-91; Fax number: +48-85-7468616; E-mail: izadom@umb.edu.pl

Received October 16, 2015; Accepted November 03, 2015; Published November 17,2015

Citation: Domyslawska I, Gindzienska-Sieskiewicz E, Chrostowski T, Klimiuk PA Sierakowski S (2015) Discontinuation of Tnf-Alfa Inhibitors in Rheumatoid Arthritis Remission. J Arthritis 4: 177. doi:10.4172/2167-7921.1000177

Copyright: ( 2015 Domyslawska I, et al. This is an open-access article distributed under the terms of the Creative Commons Attribution License, which permits unrestricted use, distribution, and reproduction in any medium, provided the original author and source are credited. 
Patients were age $\geq 18$ years (18-75 years) with a diagnosis of adultonset RA (time since diagnosis: 6 months-29 years); all had severe active RA [6]. Patients must have had active disease, defined by DAS 28 ESR $>5.1$ [7]. All had had $\geq 6$ months MTX treatment (10-25 mg/week) with a dosage of $25 \mathrm{mg} /$ week for $\geq 3$ months prior to the visit.

Patients received biological treatment according to Polish National Health Service guidelines [5]. Inclusion criteria to the study included high disease activity, insufficient response to methotrexate and/ or other sDMARDs (details in Table 1). Exclusion criteria included history of chronic infections, presence of serious viral or bacterial infections, lymphoproliferative disorder, malignancy or demyelinating disease, history of or currently active tuberculosis (TB), a positive chest radiograph for TB or a positive Quantiferon test. Patients positive for Quantiferon test could be included if active TB was ruled out and they were adequately treated for latent TB (e.g., isonicotine acid hydrazide therapy for 9 months [with vitamin B6]), with treatment initiated $\geq 1$ month prior to study drug administration. Other classical exclusion criteria for anti-TNF therapy were also applied.

\section{Sample selection and construction of study}

RA patients newly treated with biologic DMARDs were selected in this study. Patients initiated to be treated with biologic DMARD- firstline inhibitor TNF-alfa, may have been pre-treated with a nonbiologic DMARD before the baseline. Patients were monitored every 3 month. During all visits DAS28-ESR was calculated [7]. We also examined the level of Anti-cyclic Citrullinated Peptide Antibodies (anti-CCP) and presence of IgM Rheumatoid Factor (RF). Polish National Health Service guidelines state that bDMARDs shall be stopped in patients with remission if following criteria are fulfilled: there was a state of low disease activity for over 6 months, what is indicated by DAS28-ESR score $<3.2$ or DAS score $<2.4$. In such case bDMARDs treatment is discontinued and sequential therapy includes sDMARDs, preferably MTX. Patients are to be monitored and if the values of DAS28-ESR rise by over 1.2 , total value over 3.7 , bDMARDs therapy is to be renewed.

Concomitant treatment was given with analgesics, nonsteroidal antiinflammatory drugs/cyclooxygenase 2 inhibitors and corticosteroids. Oral nonbiologic DMARDs considered included MTX, cyclosporine, leflunomide, antimalarials, azathioprine, and sulfasalazine. Biologic DMARDs in the study included etanercept, infliximab, golimumab, certolizumab pegol, adalimumab, based on clinical use and Polish National Health Service guidelines.

\section{Outcome Measures}

\section{Discontinuation}

Treatment discontinuation was defined as the first occurrence of a treatment interruption of at least 60 consecutive days between the end of the one drug supply and beginning of the next prescription.

\section{Statistical analyses}

Baseline data were analysed descriptively. Characteristics of patients within each group were compared using chi-square analyses for categorical variables and $t$-tests for continuous variables.

The proportions of patients who discontinued the primary treatment, switched to another bDMARD or had any therapy changes over the study period were reported. As patients could have more than one type of treatment, the percentage of all analysed data does not always add up to $100 \%$.
The median time of the observed therapy was also reported. Median time to therapy discontinuation was calculated among those patients who incurred discontinuation as the number of days between the first date of receiving treatment and the date of the therapy stopped.

\section{Results}

\section{Baseline characteristic}

141 patients met the sample selection criteria and initiated a biologic DMARD treatment program

The average age of patients was 48.1 years, and the majority (83\%) were female. The most common comorbidities during the baseline period were osteoarthritis (approximately 26\%), hypertension (approximately 8\%), diabetes (approximately 7\%), osteoporosis (approximately 7\%) and hypothyroidism (approximately 4\%).

$65.5 \%$ of patient had positive rheumatoid factor. The largest numbers of patients (74.24\%) used Methotrexate (Table 2).

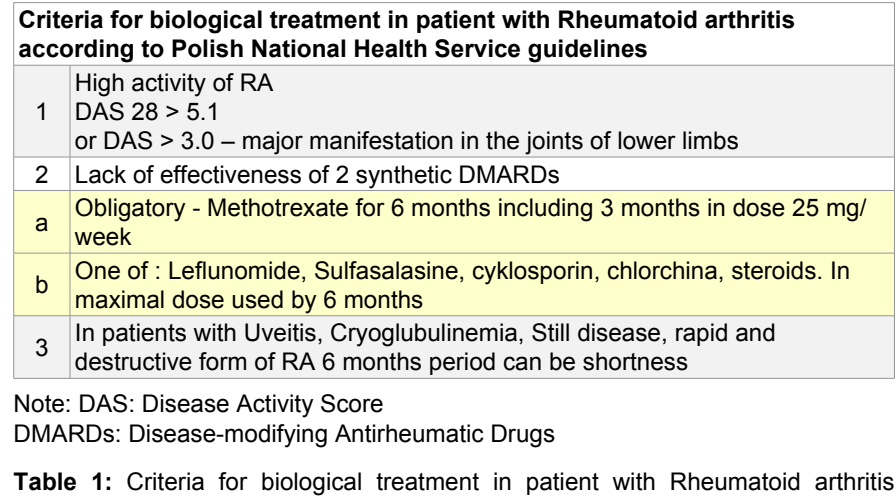
according to Polish National Health Service guidelines RA-Rheumatoid arthritis

\begin{tabular}{|c|c|c|}
\hline \multicolumn{3}{|l|}{ Baseline characteristic of study group } \\
\hline Number of patients & \multicolumn{2}{|l|}{141} \\
\hline Sex (F:M), \% Female & \multicolumn{2}{|c|}{$118: 23(83 \%)$} \\
\hline Age (years) & \multicolumn{2}{|c|}{$48.1(19.0-75.0)$} \\
\hline Presence of Rheumatoid factor (\%) & \multicolumn{2}{|l|}{65.5} \\
\hline \multirow{7}{*}{ Comorbidities (\%) } & \multicolumn{2}{|c|}{ Osteoarthritis 37 pts $(26.2 \%)$} \\
\hline & \multicolumn{2}{|c|}{ Hypertension 11 pts (7.8 \%), } \\
\hline & \multicolumn{2}{|c|}{ Diabetes 10 pts $(7.09 \%)$} \\
\hline & \multicolumn{2}{|c|}{ Osteoporosis -10 pts ( $7.09 \%)$} \\
\hline & \multicolumn{2}{|c|}{ Hypothyroidism 6 pts ( $4.25 \%$ ) } \\
\hline & \multicolumn{2}{|c|}{ Hyperthyroidism 3 pts (2.12\%) } \\
\hline & \multicolumn{2}{|c|}{ Chronic renal disease -2 pts $(1.41 \%)$} \\
\hline \multirow{6}{*}{ sDMARDs (\%) } & \multicolumn{2}{|c|}{ Methotrexate- 104 (74.46\%) } \\
\hline & \multicolumn{2}{|c|}{ Sulfasalazine- $14(9.9 \%)$} \\
\hline & \multicolumn{2}{|c|}{ Cyclosporine- 8 (5.67) } \\
\hline & \multicolumn{2}{|c|}{ Leflunomide- 9 (6.38) } \\
\hline & \multicolumn{2}{|c|}{ Azathioprine-2 (1.41\%) } \\
\hline & \multicolumn{2}{|c|}{ Antimalarials-19 13.46\%) } \\
\hline \multirow{5}{*}{ Biologicals } & \multicolumn{2}{|c|}{ Adalimumab therapy- 63 pts ( $45 \%)$} \\
\hline & \multicolumn{2}{|c|}{ Etanercept- 50 pts (35.46\%) } \\
\hline & \multicolumn{2}{|c|}{ Infliksimab- 21 pts (15\%) } \\
\hline & \multicolumn{2}{|c|}{ Golimumab- 4 pts $(2.85 \%)$} \\
\hline & \multicolumn{2}{|c|}{ Certolizumab- 3 pts $(2.12 \%)$} \\
\hline \multirow{2}{*}{$\begin{array}{l}\text { Oral corticosteroid (mean dose } 7.5 \mathrm{mg} \text { of } \\
\text { prednisolone/day) }\end{array}$} & \multirow{2}{*}{$\begin{array}{l}94 \text { pts } \\
(66.67 \%)\end{array}$} & $\begin{array}{l}26 \% \text { treated also by } \\
\text { methotrexate }\end{array}$ \\
\hline & & $\begin{array}{l}74 \% \text { treated also by other } \\
\text { sDMARDs }\end{array}$ \\
\hline
\end{tabular}

SDMARD: synthetic Disease-modifying Antirheumatic Drugs

Table 2: Baseline characteristic of study group. 
During the baseline period, $45 \%$ of patients initiated adalimumab therapy, $35.46 \%$ received etanercept, $15 \%$ received infliksimab, $2.85 \%$ received golimumab and $2.12 \%$ received certolizumab. Approximately $67 \%$ of patients used an oral corticosteroid. $26 \%$ of patients using corticosteroids were treated with methotrexate while approximately $74 \%$ were treated with other DMARDs then Methotrexate.

\section{Therapy discontinuation}

The median time of first-line therapy in our study was 378.5 days. The average DAS28-ESR value of patients qualified for treatment was - 5.95 ( \pm 1.78). Patients who stopped first-line treatment within 3 months constituted $10.7 \%$ of the total group of patients. These were patients who failed to respond to treatment within the first 3 months due to primary inefficiency - 9 patients $(6.42 \%)$, or who experienced a side effect or intolerance - 6 patients $(4.28 \%)$. Secondary failure of initial response to treatment was observed in the next 8 people before the end of the first year of treatment (5.67\%). Overall, $16 \%$ of the patients had at least one therapy change during the course of the 12-month study period. All patients who had at least one therapy discontinued change the primary biologic treatment at some point during the 12-month study period (median time: 172.7 days).

In the group of patients who responded to treatment with a firstline biological drug - 118 people (83.68\%), the median time to achieve remission or low disease activity - was 198 days. DAS28-ESR remission measured by below 2.6 was achieved in approximately $54 \%$ of patients, and low disease activity (DAS28-ESR values below 3.2 in the case of patients for whom a therapeutic target was low disease activity) was obtained in $29 \%$ of patients (Figure 1). In this group the median time to discontinuation of treatment was 452.4 day. After discontinuation of therapy relapse occurred in 104 of 139 (74.28\%) patients qualified for treatment. Disease recurrence within 12 months after the end of treatment was observed in an average 110.4 days. During this period the population of treated patients decreased by 2 persons - death ( 1 patient died due to Myocardial Infarction, 1 patient died in a car accident). The value of the DAS 28 before turning the second course of treatment averaged $4.97( \pm 1.2)$. The time to reach the next remission in this group of patients was on average 211 days. In this phase of the treatment another 11 people demonstrated secondary resistance to TNF-alfa inhibitors (7.9\%). A proportion of patients who achieved remission and low disease activity with respect to the first-line treatment was significantly lower ( $33 \%$ compared to $49 \%$ ) $\mathrm{p}=0.81$ (Figure 2 ).

35 patients $(25.17 \%)$ from the total group maintained remission longer than 12 months after the first-line treatment was stopped. The median duration of first-line treatment in this group compared to the group of patients with relapse, during the first year after discontinuation of treatment was 204.5 vs 195.4 (Figure 3). No statistically significant differences were evident in relation to the incidence of rheumatoid factor and level of anti-ccp antibodies as well as in the DAS28-ESR value in both groups (Figures 4-6).

In the group of patients with longer time of remission after the first discontinuation (>12 Mo) DAS28-ESR value was lower $(\mathrm{p}=0.93)$ and time of disease duration was shorter $(\mathrm{p}<0,001)$ than in the group of patients with a shorter remission time (Figures 6-9).

\section{Discussion}

This is the first study to examine discontinuation of TNF-alfa inhibitors in patients with RA in the Polish population. We evaluated the activity of the disease, its duration, and the duration of treatment in a group of subjects with both short and long periods of remission after the discontinuation of treatment. These observations confirmed conclusions from studies in other countries. Recurrence of disease symptom after the discontinuation of TNF-alfa therapy is very common ( $74 \%$ of patients in our study with remission). Disease activity in the period between discontinuation of the first course of treatment and start of the second course is lower but equally the percentage of patients with remission after the second course of treatment is lower compared to first course of treatment. This means than it is much more difficult to reach a similar state of remission even after only a short break in treatment.

The biological treatment of RA after achievement of remission is a multi-layer problem of great significance. From the patients' perspective, continuation ensures the highest chance of preventing recurrence and loss of quality of life. On the other hand, the admission of biological drugs increases the risk of developing adverse effects, mainly infections, hepatopathy and tumours. Compliance to prolonged therapy is also subject to question, though studies show that fear of loss of control of $\mathrm{RA}$ is one of the biggest concerns the physiological point of view and patients are generally willing to continue with chronic treatment $[8,9]$. Economic concerns are also of considerable importance, as bDMARDs treatment exceeds sDMARDs costs by a substantial margin and is deemed expensive by most health care systems [10]. The highest costs

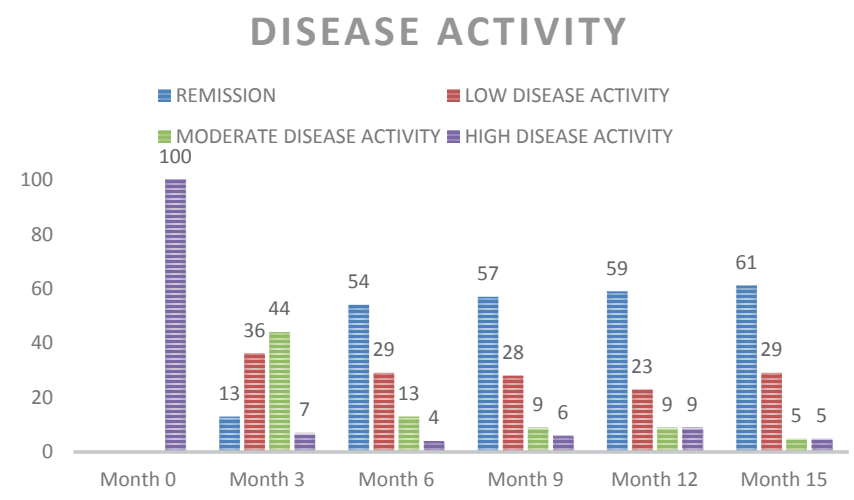

Figure 1: Disease activity measured by DAS 28

Percentage of patients with remission - DAS $28<2.6$

Low disease activity DAS 28 between 2.6 and 3.2

Moderate disease activity DAS 28 between 3.2 and 5.1

High disease activity DAS $28>5.1$

DAS- Disease activity score

\section{Remission and low disease activity during first and secound course of treatment}

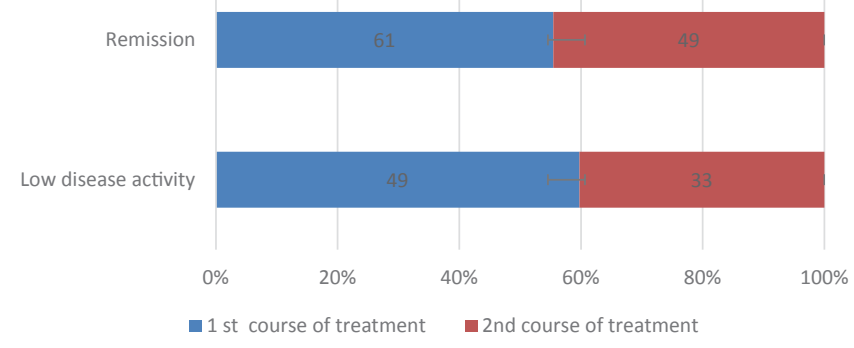

Figure 2: Remission and low disease activity during first and second course of treatment. $P=0,819331$ 
Citation: Domyslawska I, Gindzienska-Sieskiewicz E, Chrostowski T, Klimiuk PA, Sierakowski S (2015) Discontinuation of Tnf-Alfa Inhibitors in Rheumatoid Arthritis Remission. J Arthritis 4: 177. doi:10.4172/2167-7921.1000177

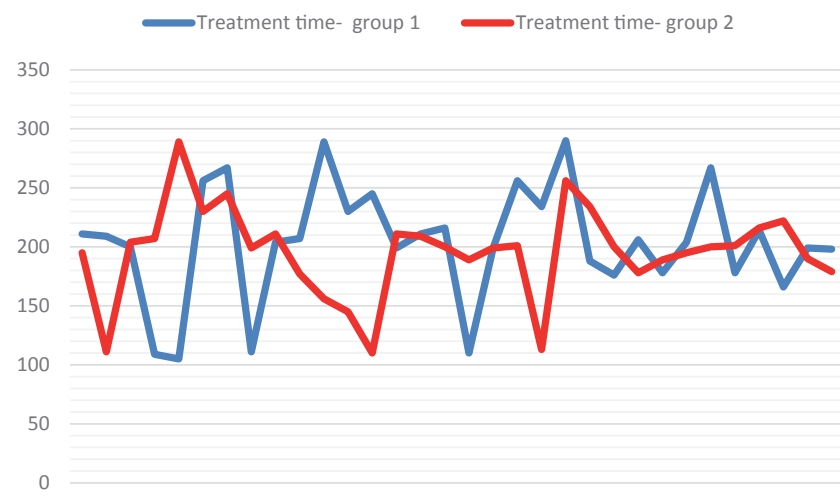

Figure 3: Medium time of treatment by first course TNF-alfa blocker to the discontinuation. $P=0,221$

Group1- group maintained remission longer than 12 months after the first-line treatment was stopped

Group2- group maintained remission shorter than 12 months after the first-line treatment was stopped

TNF-alfa- Tumor Necrosis Factor-alfa

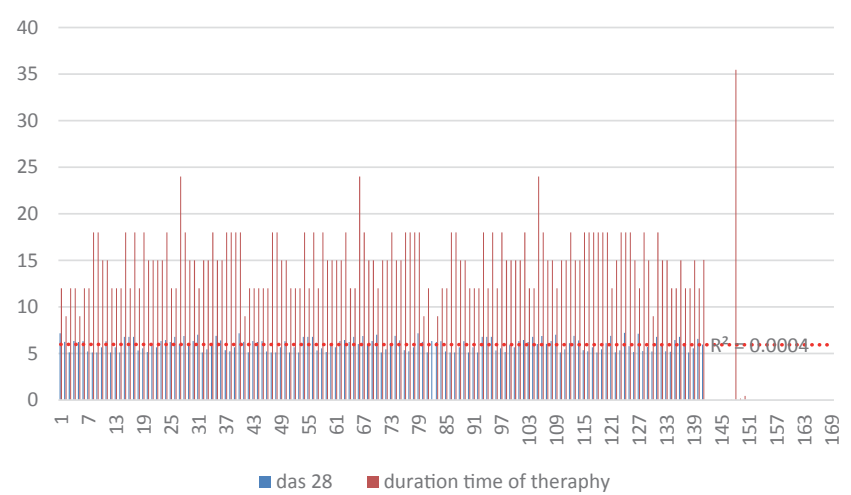

Figure 4: Relation duration time of therapy to DAS 28. $p=-0,02307$. DAS Disease activity score.

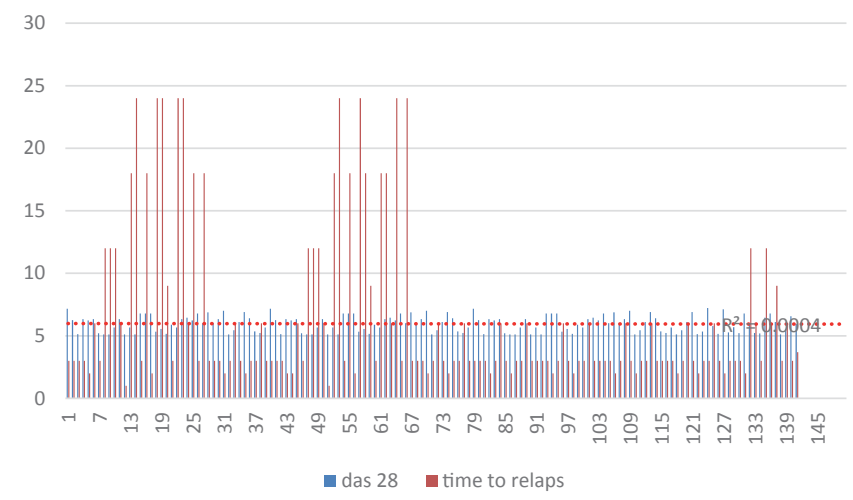

Figure 5: Relation duration time to relapse to DAS 28. $p=-0,14857$. DASDisease activity score.

are incurred during the first year of disease and in its late phase. In the TIRA study, 6 years after diagnosis RA drug costs were partially offset by decreasing outpatient visits but indirect costs remained unchanged and total costs increased [11].

The problem of discontinuation of the treatment has been a target of numerous trials. HONOR studies implied that after discontinuation of ADA it is possible to maintain a low level disease activity [12]. There was certainly a group of patients that could stop receiving biological drugs and not suffer recurrence, though that number diminished over time and the median duration of remission proved to be slightly over 20 months. A point worth noting is that no significant radiographic damage progression was observed after discontinuation of bDMARDs either in patients with persistent remission or those with recurrences $[13,14]$. However, it is questionable if discontinuation should be

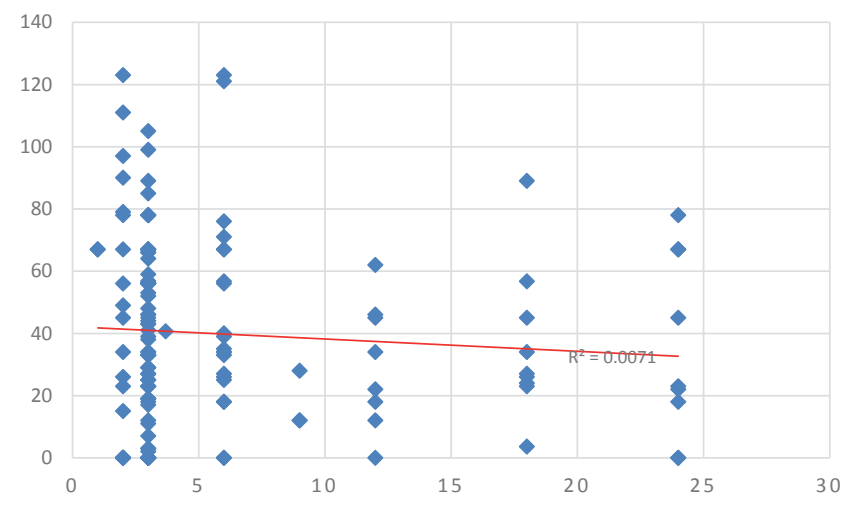

Figure 6: Relation between time to relapse and anti-CCP antibodies level $p=$ -0,02307. Anti-CCP antibodies- Anti-cyclic Citrullinated Peptide antibodies.

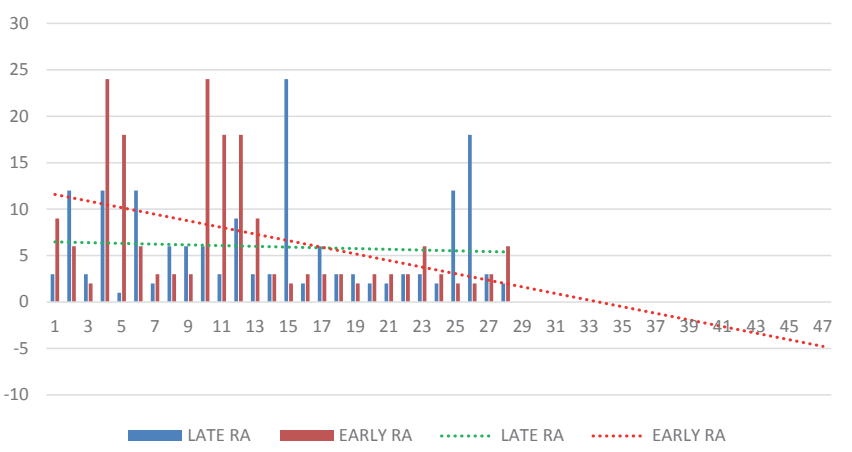

Figure 7: Time to relapse in early RA and late $R A P=0,425393$. RA-Rheumatoid arthritis.

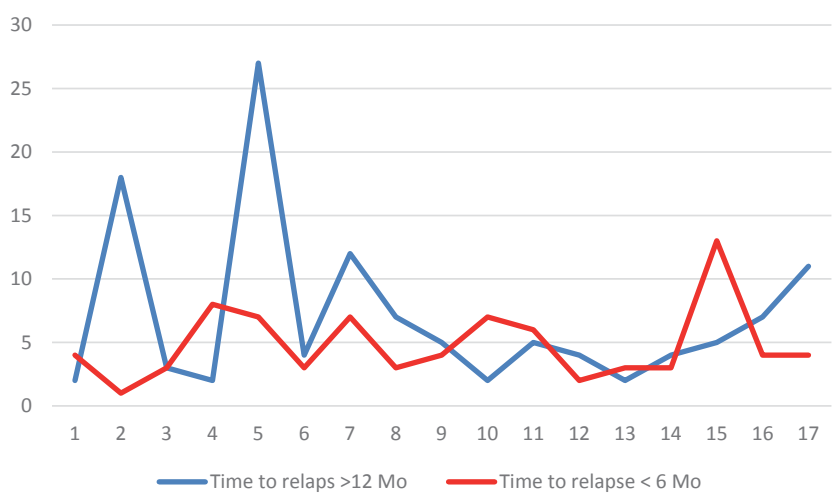

Figure 8: Value of DAS28 in patients with RA with long time and short time of remission after discontinuation of first course treatment. $P=0,930035$. RARheumatoid arthritis. DAS- Disease activity score. 


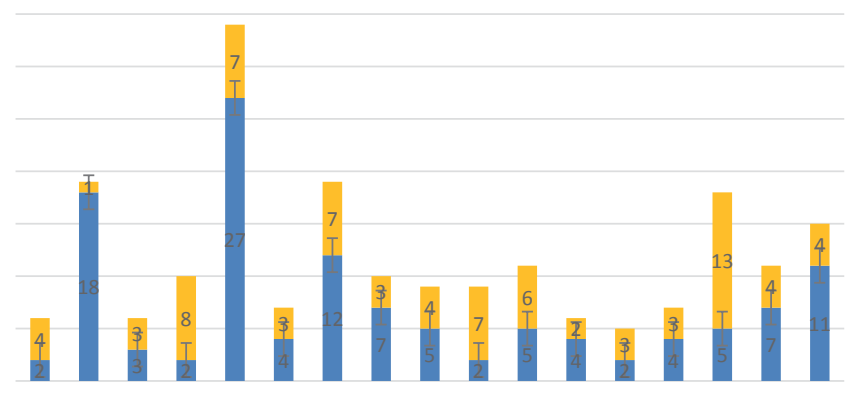

- Time to relaps $>12 \mathrm{Mo} \quad$ Time to relapse $<6 \mathrm{Mo}$

Figure 9: Disease duration (years) in patients with RA with long time and short time of remission after discontinuation of first course treatment. $\mathrm{P}<0,001^{*}$. RA-Rheumatoid arthritis.

applied to all patients, as more often than not exacerbations occur that can decrease quality of life and functional ability .

The main goal in the treatment of RA is to maintain low level disease activity [4]. It is evident that continuation of biological treatment along with synthetic drugs is much more efficient at preventing recurrences than synthetic drugs monotherapy. PERSERVE studies showed that with the usage of etanercept and methotrexate such differences may represent as much as $42.6 \%$ of patients [15]. Similar results were presented in the PRIZE study [16]. This principle was also affirmed for adalimumab and methotrexate $[17,18]$. A significant number of trials targeted the possibility of retaining LDA after discontinuing varied biological drugs and the results clearly stated that the maintenance ratio of LDA dropped significantly. In most cases resumption of the same bDMARD provided a good response [19-22].

Another attitude, which could reconcile many postulates from both approaches, is to reduce the dosage of bMARDs after reaching the point of remission [23].This would decrease costs of treatment, while providing patients with continuing disease control. Applying decreased quantities of drugs was proved to be a more successful strategy than discontinuing bMARDs. It has been shown that down-titration of dosage is possible even in patients with established RA and there is no statistically significant difference in QoL compared to patients in the full-dosage group [24-26].

To individualise therapy and provide the best care for each patient, it seems relevant to assess prognostic factors influencing the potential success of discontinuation or diminution of dosages [27]. With such knowledge we could choose the most eligible candidates for treatment discontinuation or decrease of dosage. In our study, it was demonstrated that patients with a long time period of disease duration, had a $45 \%$ higher chance of relapsing. Other trials proved that other determinants with huge negative influence are: having a high DAS before remission, lower baseline HAQ, sulfasalazine as last DMARD, shared epitope and smoking. Adversely, rapid achievement of LDA proved to be connected with better maintenance of benefits.

Controversy arises as to early disease stage. In some studies it is being connected with better control, while assessment of the Corona registry proved it does not affect maintenance of clinical benefit $[14,20,23]$. In routine daily practice, however, it is still huge problem. Only one out of five early RA patients was treatment initiated within 12 weeks of symptom onset, as recommended [28].
One very important aspect with using TNF-alfa inhibitors is connected with the immunogenicity phenomenon. Neutralizing antibodies are correlated with reduced serum drug concentrations, loss of therapeutic response, adverse events, and treatment discontinuation [29]. Frequent recession of biological treatment can be the inductor of producing neutralizing antibodies in RA patients.

Reaching remission in RA is still a very difficult and complex problem. Even in very early RA, remission without treatment is rare, many patients experience a flare of the disease during drug discontinuation.

\section{References}

1. Klareskog L, Catrina Al, Paget S (2009) Rheumatoid arthritis. Lancet 373: 659672.

2. Olsen NJ, Stein CM (2004) New drugs for rheumatoid arthritis. N Engl J Med 350: $2167-2179$.

3. Pollard L, Choy EH, Scott DL (2005) The consequences of rheumatoid arthritis: quality of life measures in the individual patient. Clin Exp Rheumatol 23: S4352.

4. Smolen JS, Landewe R, Breedveld FC, Buch M, Burmester G, et al. (2013) EULAR recommendations for the management of rheumatoid arthritis with synthetic and biological disease-modifying antirheumatic drugs: 2013 update. Ann Rheum Dis 73: 492-509.

5. http://www.nfz.gov.pl/zarzadzenia-prezesa/zarzadzenia-prezesa-nfz/ zarzadzenie-nr-82010dgl,3999.html

6. Aletaha D, Neogi T, Silman AJ, Funovits J, Felson DT, et al. (2010) Rheumatoid arthritis classification criteria: an American College of Rheumatology/European League Against Rheumatism collaborative initiative. Arthritis Rheum 62: 25692581.

7. Fransen J, Stucki G, van Riel PLCM (2003) Rheumatoid Arthritis Measures Disease Activity Score (DAS), Disease Activity Score-28 (DAS28), Rapid Assessment of Disease Activity in Rheumatology (RADAR), and Rheumatoid Arthritis Disease Activity Index (RADAI). Arthritis Rheum 49: 214-224.

8. Felson DT, Smolen JS, Wells G, Zhang B, van Tuyl LHD, et al. (2011) American College of Rheumatology/European League Against Rheumatism Provisional Definition of Remission in Rheumatoid Arthritis for Clinical Trials. Ann Rheum Dis 70: 404-413.

9. Wolfe F, Michaud K (2007) Resistance of rheumatoid arthritis patients to changing therapy: discordance between disease activity and patients' treatment choices. Arthritis Rheum 56: 2135-2142.

10. Keiserman M, Codreanu C, Handa R, Xibille-Friedmann D, Mysler E, et al (2014) The effect of antidrug antibodies on the sustainable efficacy of biologic therapies in rheumatoid arthritis: practical consequences. Expert Rev Clin Immunol 10: 1049-1057.

11. E Hallert, M Husberg , A Kalkan , T Skogh , L Bernfort (2014) Early rheumatoid arthritis 6 years after diagnosis is still associated with high direct costs and increasing loss of productivity: the Swedish TIRA project. Scand J Rheumatol 43: 177-183.

12. Tanaka Y, Hirata S, Kubo S, Fukuyo S, Hanami K, et al. (2015) Discontinuation of adalimumab after achieving remission in patients with established rheumatoid arthritis: 1-year outcome of the HONOR study. Ann Rheum Dis 74: 389-395.

13. Tanaka Y, Takeuchi T, Mimori T, Saito K, Nawata M, et al. (2010) Discontinuation of infliximab after attaining low disease activity in patients with rheumatoid arthritis: RRR (remission induction by Remicade in RA) study. Ann Rheum Dis 69: 1286-1291.

14. van den Broek M, Lems WF, Allaart CF (2012) BeSt practice: the success of early-targeted treatment in rheumatoid arthritis. Clin Exp Rheumatol 30: S3538.

15. Smolen JS, Nash P, Durez P, Hall S, llivanova E, et al. (2013) Maintenance, reduction, or withdrawal of etanercept after treatment with etanercept and methotrexate in patients with moderate rheumatoid arthritis (PRESERVE): a randomised controlled trial. Lancet 381: 918-929.

16. EmeryP, Hammoudeh M, FitzGerald O, Combe B, Martin Mola E, et al. (2013) Assessing maintenance of remission with reduced dose etanercept plus 
Citation: Domyslawska I, Gindzienska-Sieskiewicz E, Chrostowski T, Klimiuk PA, Sierakowski S (2015) Discontinuation of Tnf-Alfa Inhibitors in Rheumatoid Arthritis Remission. J Arthritis 4: 177. doi:10.4172/2167-7921.1000177

methotrexate, methotrexate alone, or placebo in patients with early rheumatoid arthritis who achieved remission with etanercept and methotrextate: the prize study. Ann Rheum Dis 72: A399.

17. Kavanaugh A, Emery P, Fleischmann R, van Vollenhoven, RF, Pavelka K, et al. (2011) Withdrawal of Adalimumab in Early Rheumatoid Arthritis Patients Who Attained Stable Low Disease Activity with Adalimumab Plus Methotrexate: Results of a Phase 4, Double-Blind, Placebo-Controlled Trial. [abstract] Arthritis Rheum 63: 169.

18. Harigai M, Takeuchi T, Tanaka Y, Matsubara T, Yamanaka H, et al. (2012) Discontinuation of adalimumab treatment in rheumatoid arthritis patients after achieving low disease activity. Mod Rheumatol 22: 814-822.

19. Smolen JS, Emery P, Ferraccioli GF, Samborski W, Berenbaum F, et al. (2014) Certolizumab pegol in rheumatoid arthritis patients with low to moderate activity: the CERTAIN double-blind, randomised, placebo-controlled trial. Ann Rheum Dis.

20. van den Broek M, Klarenbeek NB, Dirven L, van Schaardenburg D, Hulsmans HJM, et al. (2011) Discontinuation of infliximab and potential predictors of persistent low disease activity in patients with early rheumatoid arthritis and disease activity score-steered therapy: subanalysis of the BeSt study. Ann Rheum Dis 70: 1389-1394.

21. Nampei A, Nagayama $Y$ (2013) Discontinuation of tocilizumab after attaining remission in patients with rheumatoid arthritis. Ann Rheum Dis 72: 877.

22. Brocq O, Millasseau E, Albert C, Grisot C, Flory P, et al. (2009) Effect of discontinuing TNFalpha antagonist therapy in patients with remission of rheumatoid arthritis. Joint Bone Spine 76: 350-355.
23. Kavanaugh A, Lee SJ, Curtis JR, Greenberg JD, Kremer JM, et al. (2015) Discontinuation of tumour necrosis factor inhibitors in patients with rheumatoid arthritis in low-disease activity: persistent benefits. Data from the Corrona registry. Ann Rheum Dis 74: 1150-1155

24. Tanaka Y, Hirata S, Saleem B, Emery P (2013) Discontinuation of biologics in patients with rheumatoid arthritis. Clin Exp Rheumatol 31: S22-27.

25. van der Maas A, Kievit W, van den Bemt BJ, van den Hoogen FH, van Rie $\mathrm{PL}$, et al. (2012) Down-titration and discontinuation of infliximab in rheumatoid arthritis patients with stable low disease activity and stable treatment: an observational cohort study. Ann Rheum Dis 71: 1849-1854

26. Fautrel B, Gandjbakhch F, Foltz V, Pham T, Morel J, et al. (2013) Targeting the lowest efficacious dose for rheumatoid arthritis patients in remission: clinical and structural impact of a stepdown strategy trial based on progressive spacing of TNF-blocker injections (STRASS trial). Ann Rheum Dis.

27. Smolen JS, Aletaha D (2015) Rheumatoid arthritis therapy reappraisal: strategies, opportunities and challenges. Nat Rev Rheumatol 11: 276-289.

28. De Cock D, Meyfroidt S, Joly J, Van der Elst K, Westhovens R, et al. (2014) A detailed analysis of treatment delay from the onset of symptoms in early rheumatoid arthritis patients. Scand J Rheumatol 43: 1-8.

29. Borrás-Blasco J, Navarro Ruiz A (2015) Dose modification of anti-TNF in rheumatoid arthritis and estimated economical impact: a review of observational studies. Expert Rev Pharmacoecon Outcomes Res 15: 71-79. 